\title{
Research on Supporting Measure at Intersection of Inclined Shaft and Major Tunnel in Highway
}

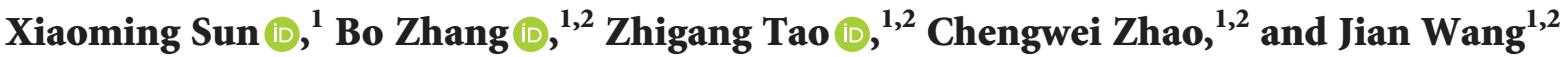 \\ ${ }^{1}$ State Key Laboratory for Geomechanics \& Deep Underground Engineering, Beijing 100083, China \\ ${ }^{2}$ School of Mechanics and Civil Engineering, China University of Mining \& Technology, Beijing 100083, China
}

Correspondence should be addressed to Xiaoming Sun; sxm138011@163.com and Zhigang Tao; silingfa123@163.com

Received 26 August 2020; Revised 10 October 2020; Accepted 20 October 2020; Published 10 November 2020

Academic Editor: Jia-wen Zhou

Copyright (C) 2020 Xiaoming Sun et al. This is an open access article distributed under the Creative Commons Attribution License, which permits unrestricted use, distribution, and reproduction in any medium, provided the original work is properly cited.

The deformation characteristics of the rock mass in the intersection between the Muzhailing highway tunnel and the inclined shaft is a complicated three-dimensional problem. Under the influence of high geostress, large deformation hazards may occur in the surrounding rock. Taking this as the research background, this paper analyzes the deformation mechanism of surrounding rock before and after prestressed anchor cable support through numerical simulation. Then, through theoretical analysis, a new tunnel support method using high prestressed constant resistance and large deformation anchor cable was proposed. The field monitoring results show that the constant resistance and large deformation anchor cable support can well control the deformation of surrounding rock, and the maximum deformation is within $300 \mathrm{~mm}$. At the same time, the constant resistance anchor cable can always maintain a high prestress, which makes the stress of the surrounding rock uniform, and reduces the risk of damage to the steel arch due to local pressure. Moreover, the support method limits the expansion of the plastic zone and improves the overall stability of the surrounding rock.

\section{Introduction}

The tunnel intersection support is a key concern in the tunnel construction, because the area of the tunnel at the intersection is large; once large deformation occurs, it will be difficult to repair; even if it can be repaired, there is also the risk of a sudden collapse of the tunnel vault.

Researchers have done a lot of research on tunnel surrounding rock deformation and support methods. Hoek et al. [1] studied the tunnel deformation characteristics under different buried depths. They considered that rock mass strength and ground stress are the key factors affecting the stability of tunnel surrounding rock. Aydan et al. [2] summarized the mechanical mechanism of three kinds of surrounding rock in squeezing phenomenon: complete shear failure, bending failure, and shear sliding failure. Kang et al. [3] used the Flac3D to analyze the deformation characteristics and stress distribution of the surrounding rock at the intersection of winch house in deep-buried soft rock roadway. Then, a new type of hollow grouting anchor cable support system was introduced, which achieved good results. Tao et al. [4] studied the failure mechanism of soft rock roadway in steep layered strata. They analyzed the failure characteristics of different steeply inclined layered soft rocks roadways under the influence of high lithostatic stress and horizontal tectonic stress. He [5] studied the deformation and failure characteristics of surrounding rock in $45^{\circ}$ inclined rock strata and analyzed the temperature characteristics of surrounding rock in the process of roadway failure by using infrared thermography. Liu et al. [6] considered that the rock mass behavior at the intersection of the adit and the main tunnel is a complex threedimensional problem, and the increase of support load and tunnel deformation may endanger the stability of the tunnel during the construction process. Wang et al. [7] studied the reinforcement mechanism of bolts through DEM numerical analysis. The research shows that the bolts can effectively control the rock failure and that increasing the number of bolts can improve the reinforcement effect of the surrounding rock. Meng et al. [8] considered rock mass and 
rock bolts as a new homogeneous, isotropic, parameters strengthened equivalent composite material. The research shows that anchor bolt has an important effect on plastic zone size and displacement of the surrounding rock. Xu et al. [9] designed a new-type supporting system of grid steel frame-core tube for the large deformation of the tunnel. Hsiao et al. [10] conducted 75 cases of 3D numerical analysis, established the evaluation criteria for the impact of intersections on the tunnel performance, and proposed support design suggestions for different geological conditions. Lin et al. [11] conducted the stability analysis of large-span tailrace bifurcation tunnels and proposed a new nonlinear reinforcement analysis method, which was used in the design of reinforced concrete lining and rock bolts.

The research on control measures of soft rock tunnel mainly focuses on passive support, which is to increase the strength of supporting structure, while the study of active support measures to improve the strength of rock mass is less. This paper introduced a new active support method for the high geostress soft rock tunnel. To understand the deformation mechanism of the inclined layered surrounding rock at the intersection of Muzhailing tunnel and inclined shaft 3\#, the Flac3D numerical analysis was conducted. Then, through theoretical analysis, the relationship between the constant resistance anchor cable support related parameters and the surrounding rock bearing capacity was studied. Based on the above analysis, a high prestressed constant resistance anchor cable support strategy for tunnel intersection was proposed. After field application and monitoring tests, the results show that this method can effectively control the stability of the surrounding rock at the tunnel intersection.

\section{Project Overview}

2.1. Location and Geological Condition. Muzhailing tunnel is located in the south of Gansu Province, China (Figure 1). It is a part of the Lanzhou-Haikou Expressway. The total length of the tunnel is $15.226 \mathrm{~km}$, and the maximum buried depth is $629.1 \mathrm{~m}$. The tunnel passes through the middle and low mountainous areas in the western Qinling Mountains. The terrain is generally high in the north and low in the south, with steep mountains. The surrounding rock of the tunnel is mainly composed of thin-layer carbonaceous slate and passes through 12 fault fracture zones (Figure 2). Through geological investigation, the self-weight stress of surrounding rock is $15.7 \mathrm{MPa}$, and the maximum horizontal principal stress is $24.95 \mathrm{MPa}$. The strength of rock mass is less than $30 \mathrm{MPa}$, and the dip angle of rock stratum is between $30^{\circ}$ and $45^{\circ}$ (Figure 3), and it has the characteristics of soft rock such as disintegration, rheology, and engineering disturbance sensitivity. Therefore, large deformation disasters of surrounding rock may occur during tunnel construction.

2.2. Original Support Measures of Tunnel. The original supporting principle of the tunnel is NATM. The intersection was excavated by the pilot excavation method. After entering the main tunnel, three-bench excavation was used. The original tunnel support method was "grouting bolt + steel arch (Figure 4)." During the construction of the tunnel, the vault at the intersection of the inclined shaft $2 \#$ and the major tunnel was slightly deformed (Figure 5(a)), and the deformation tended to develop. At the same time, the inclined shaft $3 \#$ also had large deformation in different degrees (Figure 5(b)). The stratum conditions of inclined shaft $3 \#$ and inclined shaft $2 \#$ are similar. Therefore, the intersection of inclined shaft $3 \#$ and the major tunnel was prone to large soft rock deformation disasters. In this paper, the intersection of the inclined shaft $3 \#$ and the major tunnel with the intersecting angle of $90^{\circ}$ is selected as the research object to study the control measures of large deformation of surrounding rock at tunnel intersection.

\section{Numerical Analysis}

3.1. Numerical Modeling. Prestressed anchor cables have been widely used in coal mine roadway support. Before the support measure is proposed, the surrounding rock characteristics after excavation and under prestressed anchorage support are simulated, respectively.

Based on the Mohr-Coulomb failure criterion, a ubiquitous joint model was established in Flac3D to analyze the deformation and failure characteristics of surrounding rock with a dip angle. The dip angle of the rock layer was set to $30^{\circ}$ (Figure 6). According to the geological survey data, the horizontal stress was set at $12 \mathrm{MPa}$ in the $x$-axis direction and $21 \mathrm{MPa}$ in the $y$-axis direction, while the vertical stress was set to be $12 \mathrm{MPa}$. The tunnel excavation process was a one-time excavation, because the site construction was three-bench excavation, and the excavation length was less than $1 \mathrm{~m}$; then, the primary support was carried out, which was a small footage excavation, and the amount of deformation here was very small. The inverted arch used elastic solid modeling to simulate concrete, and shell elements to simulate lining. Anchor cable support used two lengths of $5 \mathrm{~m}$ and $10 \mathrm{~m}$. The prestress was set to $350 \mathrm{kN}$. The numerical model is shown in Figure 7.

According to Hoek's GSI geological classification index method, the rock strength and joint parameters of laboratory tests are transformed into model calculation parameters by the following formula $[12,13]$. The parameters of anchor cable are material parameters without reduction. The main parameter values are shown in Tables 1 and 2:

$$
\begin{aligned}
\frac{E_{r m}}{E_{i}} & =\left(0.02+\frac{(1-D) / 2}{1+e^{((60+15 D-\mathrm{GSI} / 11)}}\right), \\
\sigma_{c \text { mass }} & =\sigma_{c i} \frac{m_{b}+4 s-a\left(m_{b}-8 s\right)}{2(1+a)(2+a)}\left(\frac{m_{b}}{4+s}\right)^{a s-1}, \\
m_{b} & =m_{i} \exp \left(\frac{\mathrm{GSI}-100}{28-14 D}\right), \\
S & =\exp \left(\frac{\mathrm{GSI}-100}{9-3 D}\right) \\
a & =\frac{1}{2}+\frac{1}{6\left(e^{(\mathrm{GSI} / 15)}-e^{(20 / 3)}\right)} .
\end{aligned}
$$




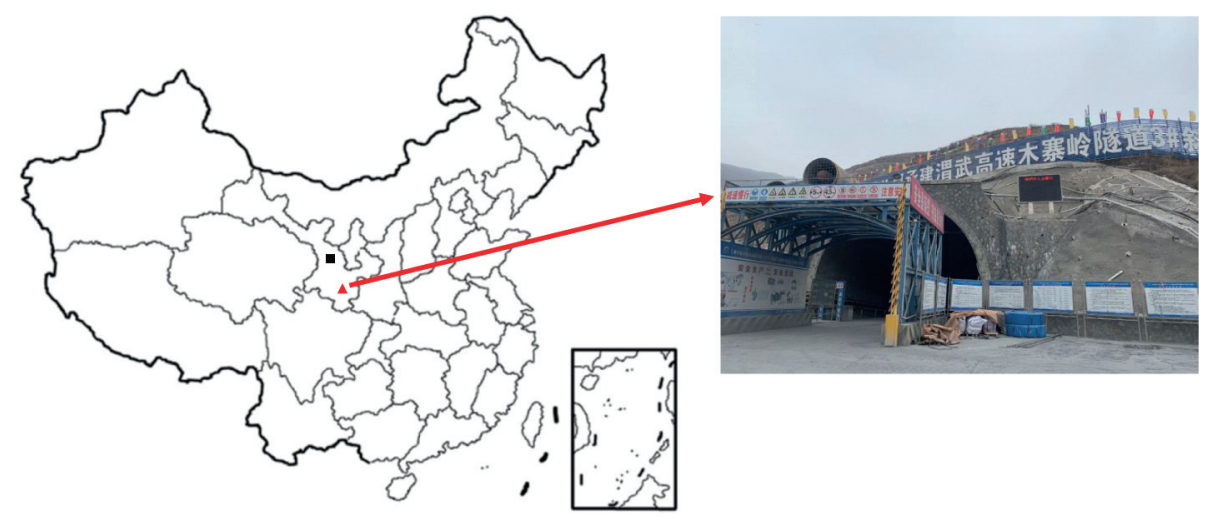

- Gansu Province

A Location of inclined shaft $3 \#$

Figure 1: Location of the tunnel.

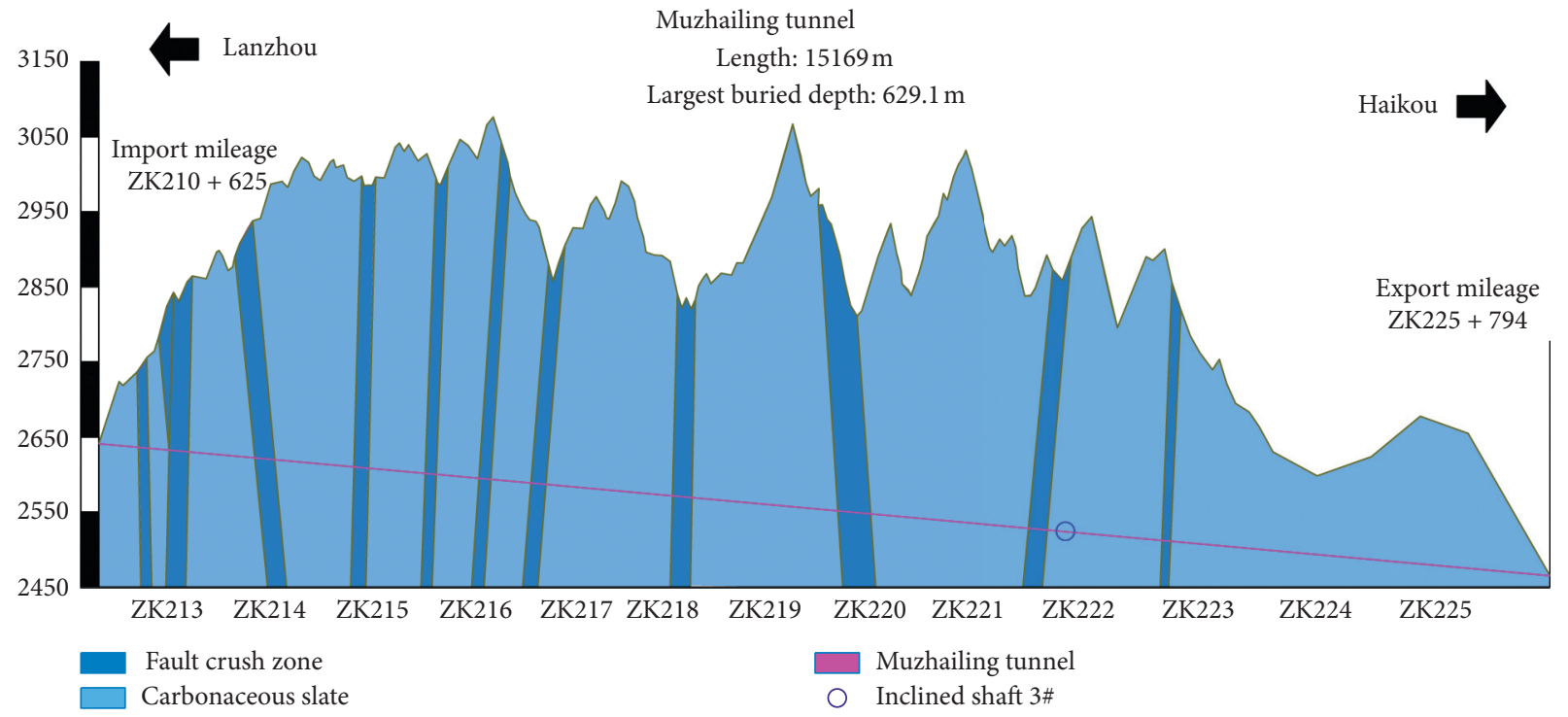

FIgURE 2: Stratigraphic condition of Muzhailing tunnel.

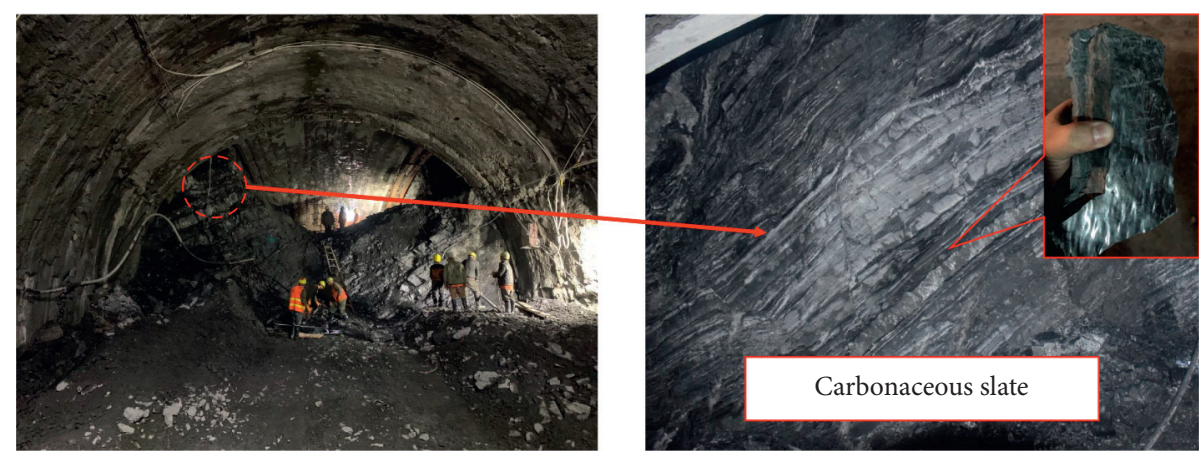

FIGURE 3: Surrounding rock exposure at the intersection of the tunnel.

In the formula, $E_{r m}$ is the elastic modulus of the rock mass, $\sigma_{c \text { mass }}$ is the uniaxial compressive strength of rock mass, GSI is the geological strength index, $E_{i}$ is the deformation modulus of rock, and $\sigma_{c i}$ is the uniaxial compressive strength of intact rock; the damage coefficient of rock mass $D=0.5$. In the calculation of joint parameters, 

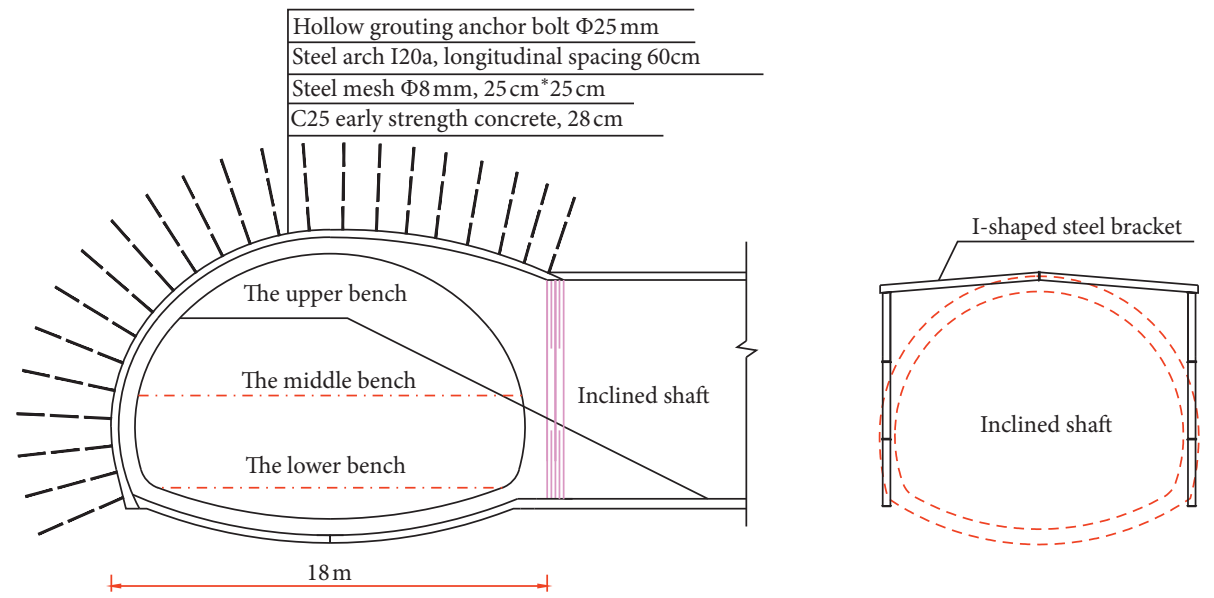

FiguRE 4: Original support design of intersection.
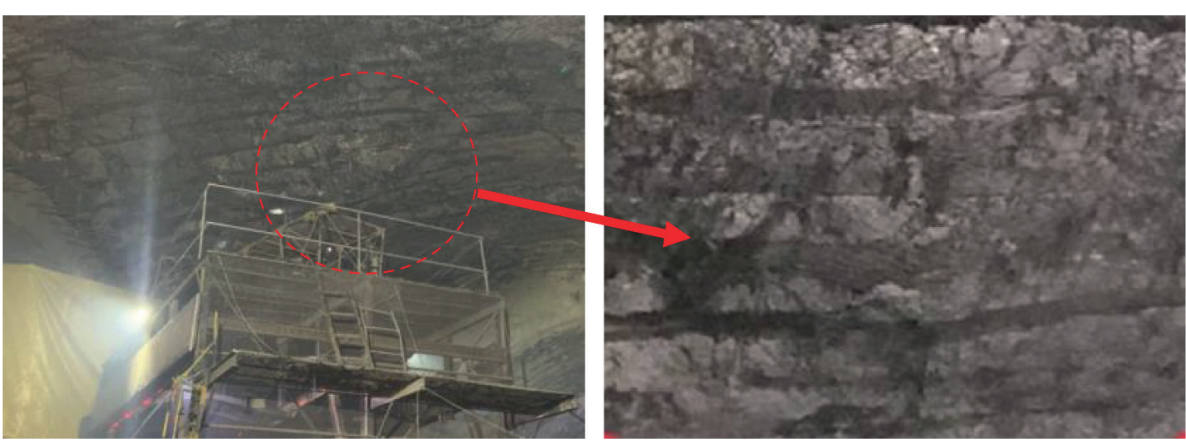

(a)
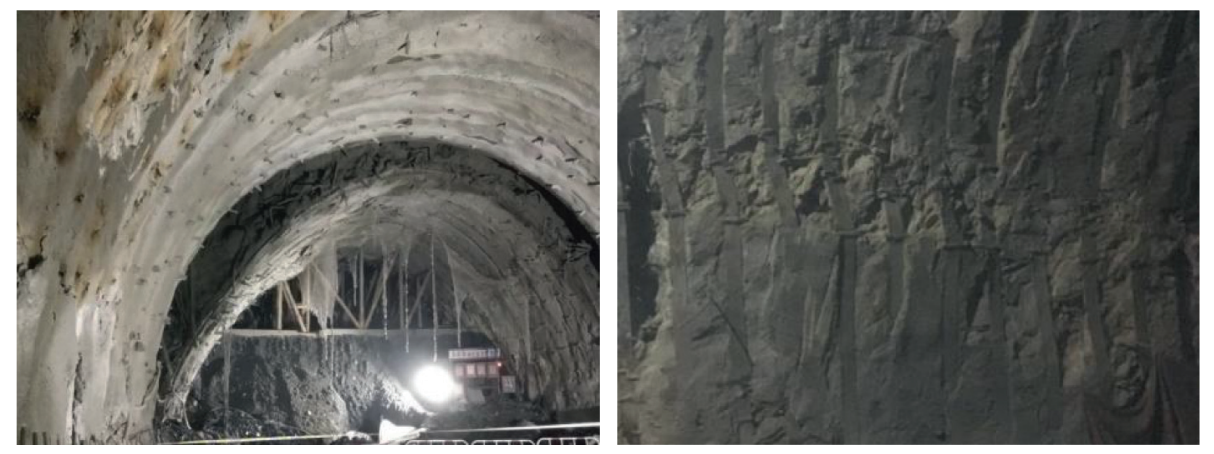

(b)

FIGURE 5: Photos of deformation and damage. (a) Deformation of the vault at the intersection. (b) Large deformation of inclined shaft 3\#.

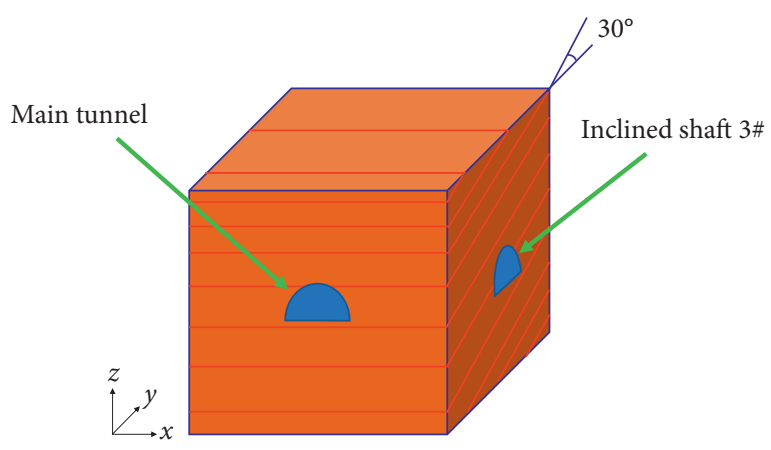

Figure 6: Dip angle of tunnel rock. the characteristic element $\Delta Z_{\min }=0.8$. The parameter calculation formula is as follows:

$$
\begin{aligned}
K & =\frac{E}{3(1-2 \mu)}, \\
G & =\frac{E}{2(1+\mu)}, \\
K_{n} & =10\left[\frac{K+(3 / 4) G}{\Delta z_{\text {min }}}\right], \\
K_{s} & =0.4 K_{n} .
\end{aligned}
$$




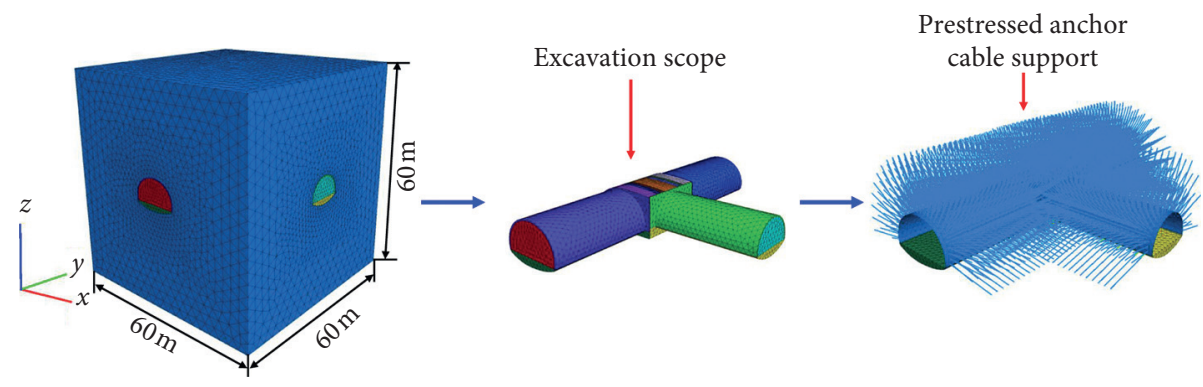

FiguRE 7: Numerical model of tunnel intersection.

TABLE 1: Computation parameters of materials.

\begin{tabular}{lcccccc}
\hline Parameter & Density $\left(\mathrm{kg} / \mathrm{m}^{3}\right)$ & Bulk modulus $(\mathrm{GPa})$ & Shear modulus $(\mathrm{GPa})$ & Cohesion $(\mathrm{MPa})$ & Frictional angle $\left(^{\circ}\right)$ & Tensile strength $(\mathrm{MPa})$ \\
\hline Rock & 2500 & 0.44 & 0.25 & 1.7 & 22 & 0.6 \\
Rock joint & - & 2 & 1 & 0.1 & 25 & 0.05 \\
\hline
\end{tabular}

TABLE 2: Computation parameters of cable.

\begin{tabular}{|c|c|c|c|c|c|c|}
\hline Parameters & $\begin{array}{l}\text { Density } \\
\left(\mathrm{kg} / \mathrm{m}^{3}\right)\end{array}$ & Elastic modulus (GPa) & Cross-sectional area $\left(\mathrm{cm}^{2}\right)$ & Stiffness (MPa) & $\begin{array}{l}\text { Cohesive } \\
(\mathrm{kN} / \mathrm{m})\end{array}$ & Tensile strength $(\mathrm{kN})$ \\
\hline Cable & 7000 & 200 & 3.801 & 20 & 1000 & 600 \\
\hline
\end{tabular}

The slice plane 1 is obtained by cutting the main tunnel model longitudinally. The slice plane 2 is obtained by cutting the model along the incline shaft trend. These two tunnel sections are used to demonstrate the stress and displacement distribution characteristics, as shown in Figure 8.

3.2. Analysis of Surrounding Rock Stress. As shown in Figures 9 and 10, the stress concentration area in the vault of the intersection was the main stress release area after the tunnel excavation. Under the support of prestressed anchor cable, the stress of surrounding rock was kept at a high value, close to the original rock stress, and the stress release zone of surrounding rock decreased. Therefore, prestressed anchor cable improves the strength of the surrounding rock.

3.3. Analysis of Surrounding Rock Displacement. According to Figures 11 and 12, in the region where the contour was denser, the displacement was more intense, and the maximum displacement was more than $1 \mathrm{~m}$. Due to the inclination of the stratum, the deformation of the surrounding rock at the intersection was generally asymmetric, which was the same as the deformation position of the vault at the intersection of inclined shaft $2 \#$ and main tunnel (Figure 5(a)). Under the support of prestressed anchor cable, the displacement and deformation area of surrounding rock were reduced.

3.4. Analysis of Plastic Zone and Axial Force of Anchor Cable. From Figure 13, the plastic zone of the surrounding rock expanded widely after excavation, mainly concentrated at the vault and invert. However, under the support of

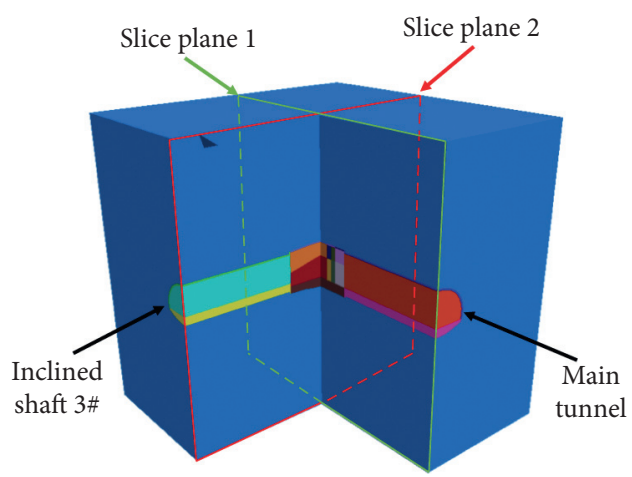

Figure 8: Location of slice plane.

prestressed anchor cable, the plastic zone of surrounding rock decreases. The stability of the surrounding rock was controlled under the support of prestressed anchor cable, but as shown in Figure 14, the axial force of the anchor cable exceeded the yield strength of the anchor cable after the prestress was applied. During the construction, a large number of prestressed anchor cables were pulled out (Figure 15). Prestressed anchor cables cannot maintain the stability of the surrounding rock for a long time. Therefore, more effective material devices should be needed to solve this problem.

\section{Tunnel Support Measure}

4.1. Support Mechanism. The prestressed anchoring support theory system mainly includes suspension theory, combined beam theory, combined arch theory, broken rock zone 


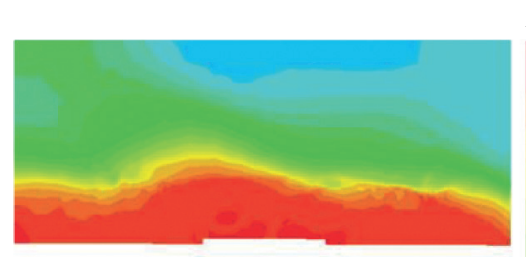

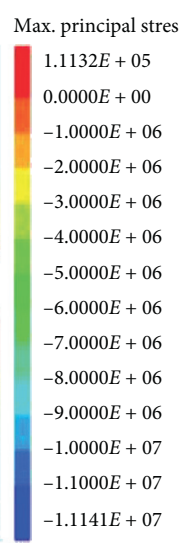

(a)

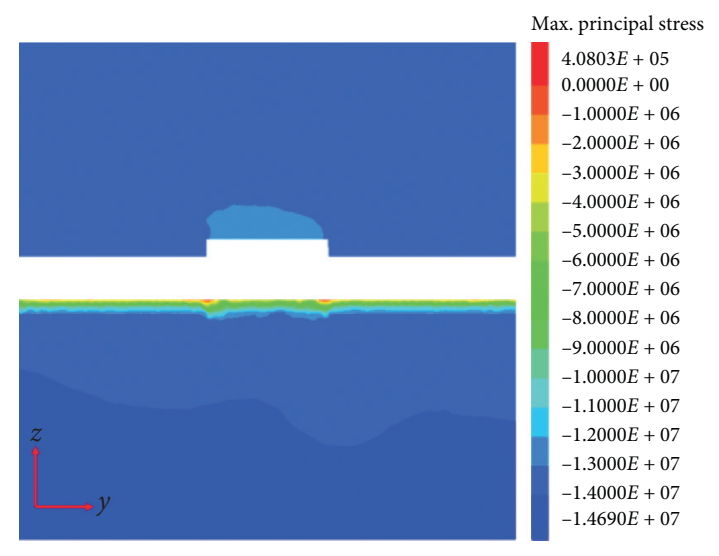

(b)

Figure 9: Maximum principal stress (slice plane 1). (a) Without support. (b) Prestressed anchor cable support.

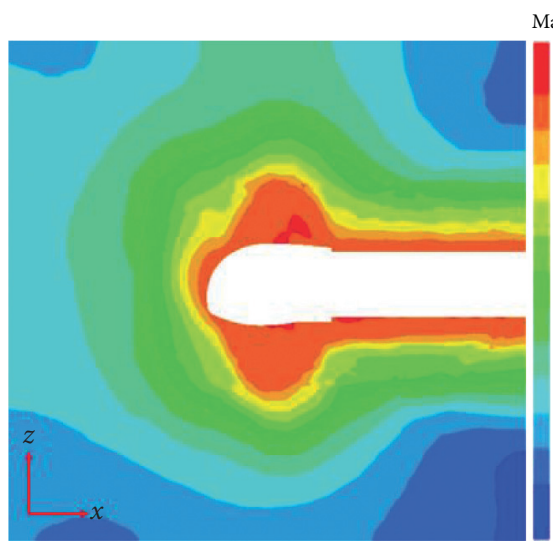

(a)
Max. principal stres

$1.1132 E+05$
$0.0000 E+00$
$-1.0000 E+06$
$-2.0000 E+06$
$-3.0000 E+06$
$-4.0000 E+06$
$-5.0000 E+06$
$-6.0000 E+06$
$-7.0000 E+06$
$-8.0000 E+06$
$-9.0000 E+06$
$-1.0000 E+07$
$-1.1000 E+07$
$-1.1141 E+07$

$-1.1141 E+07$

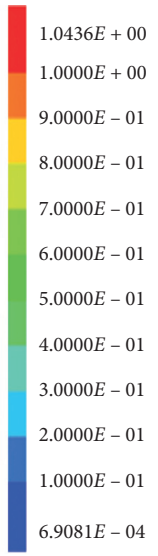

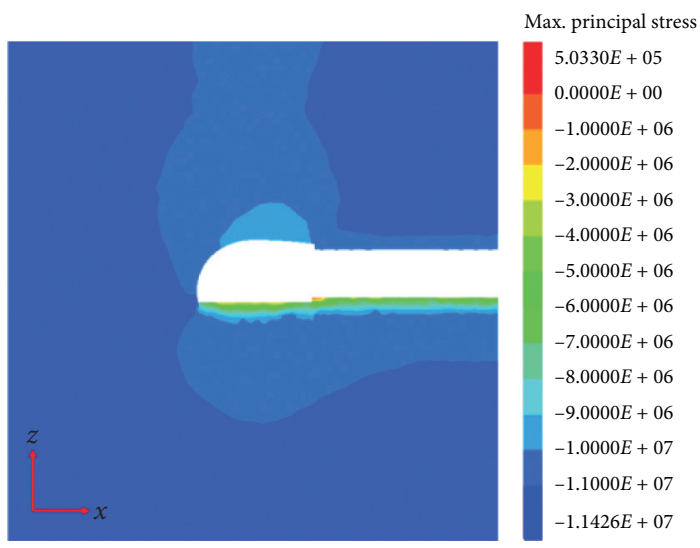

(b)

FIgURE 10: Maximum principal stress (slice plane 2). (a) Without support. (b) Prestressed anchor cable support.

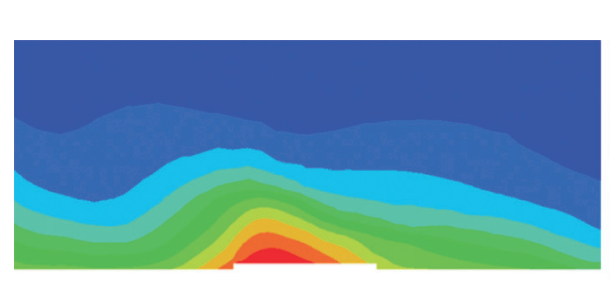

(a)

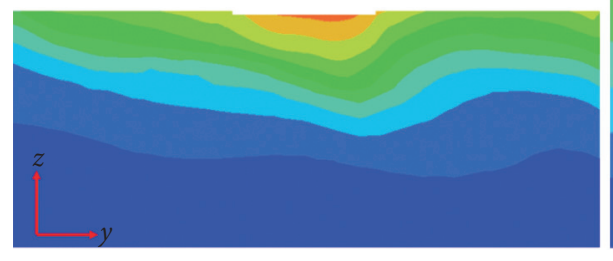

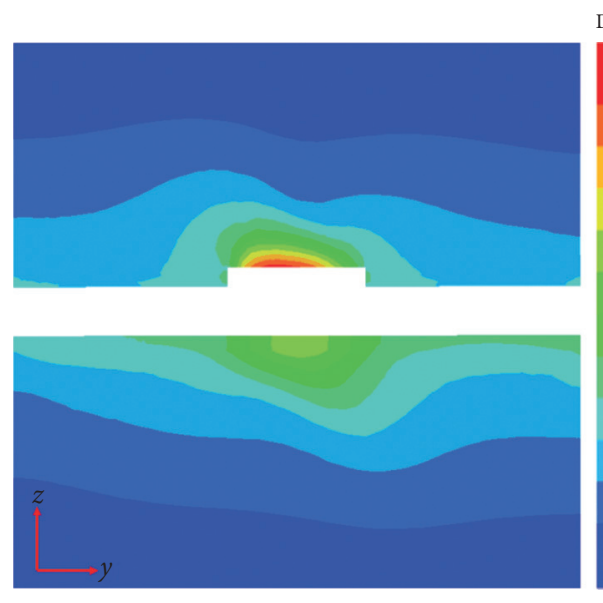

Displacement

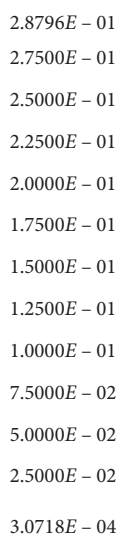

(b)

FIGURE 11: Displacement of surrounding rock (slice plane 1). (a) Without support. (b) Prestressed anchor cable support. 


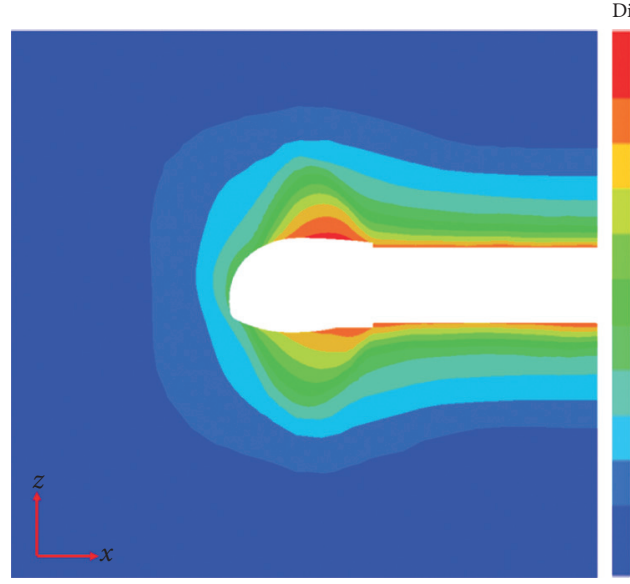

(a)

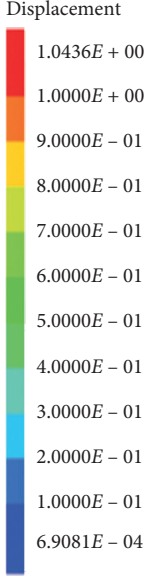

FIGURE 12: Displacement of surrounding rock (slice plane 2).

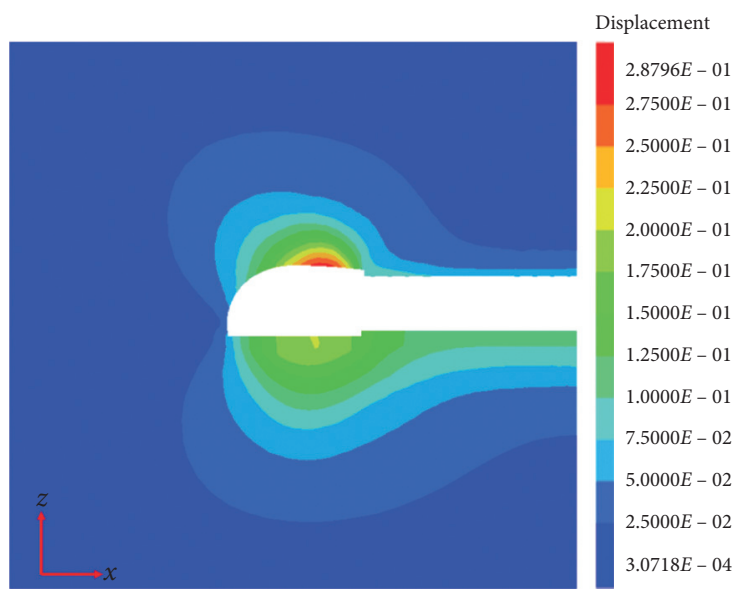

(b) theory, etc. [14]. When the rock layer is thin, the rock layer can be regarded as multiple simply supported beams stacked together, and the prestressed anchor cable can connect multiple simply supported beams in series. After being anchored by prestressed anchor cable, the extrusion force and friction force between layers can be increased, and the scattered beams exist in the form of composite beams. The prestressed anchor cable can also suspend the loose and broken rock mass on the stable rock mass to prevent the occurrence of delamination.

In the deep-buried soft rock tunnel project, to effectively control the large deformation of the surrounding rock, it is necessary to take some measures to improve the bearing capacity of the surrounding rock [15]. The prestressed anchor cable can rapidly improve the bearing capacity of the surrounding rock. After the anchor cable is prestressed, the rock mass between the anchor cables can be compressed to form a compression arch structure. If a longer anchor cable is added to the surrounding rock, it will not only strengthen the original compression arch structure but also increase its high bearing capacity. The long and short anchor cable support form a two-layer composite compression arch structure, which greatly improves the bearing capacity of the surrounding rock and transfers the shallow stress of the surrounding rock to the deep part of the surrounding rock, so that the shallow rock and the deep rock can reach a coordinated working state, and further stabilize the surrounding rock. This structure can be called a double-layer composite arch structure (Figure 16).

Gong et al. [15] and Yu et al. [16] studied the reasonable parameters of composite arch support and obtained the bearing capacity formula of a double-layer composite arch.

$$
q_{o}=\frac{1+\sin \varphi_{b}}{1-\sin \varphi_{b}}\left[\frac{Q_{l}\left(L_{l}-D_{a}^{\prime}\right)}{D_{a}^{\prime} D_{b}^{\prime}\left(R+L_{l}-D_{a}^{\prime}\right)}+\frac{Q_{s}\left(L_{s}-D_{a}\right)}{D_{a} D_{b}\left(R+L_{s}-D_{a}\right)}\right],
$$

where $Q_{l}, Q_{s}$ are the pulling force $(\mathrm{kN})$ of long and short anchor cables, respectively, $D_{a}^{\prime}, D_{b}^{\prime}$ are the spacing and row spacing of long anchor cables $(\mathrm{m}), D_{a}, D_{b}$ are the spacing and row spacing of short anchor cables, respectively $(\mathrm{m}), L_{l}$, $L_{s}$ are the length of the long and short anchor cables $(\mathrm{m}), R$ is the radius of the tunnel $\operatorname{arch}(\mathrm{m})$, and $\varphi_{b}$ is the internal friction angle of the fragmented rock mass $\left({ }^{\circ}\right)$. The formula clearly shows the relationship between the bearing capacity of composite arch and lithology, tunnel size, and anchor cable support parameters.

Under the condition that the surrounding rock does not produce significant deviatoric pressure and expansion force, the loose load $q$ of the deep-buried tunnel is estimated based on the "Specifications for Design of Highway Tunnels JTG 3370.1-2018," and considering the influence of the grade and span of the surrounding rock. The rock mass covered by the anchor cable is regarded as the reinforcement structure of the tunnel, and we take it into the tunnel span, thus obtaining the following formula:

$$
q=0.45 \times 2^{s-1} \times \gamma\left[1+0.1 \times\left(L_{l}+B-5\right)\right],
$$

where $s$ is the grade of the surrounding rock, $\gamma$ is the weight of the surrounding rock, and $B$ is the span of the tunnel. By comparing the values of $q$ and $q_{o}$, when $q_{o} \geq q$, the anchor cable support can maintain the stability of the surrounding rock.

4.2. A New Kind of Prestressed Anchor Cable. The new support scheme uses a constant resistance large deformation anchor cable (Figure 17(a)), which is a negative Poisson's ratio anchor cable (NPR anchor cable). The difference between this anchor cable and other anchor cables is the addition of a constant resistance device. As shown in Figure 17(b), due to the existence of the constant resistance device, the locking device of the anchor cable can slide in the constant resistance device, so that the outer diameter of the constant resistance device expands, thereby exhibiting a negative Poisson's ratio effect [17]. The constant resistance against slippage is provided by the friction of the inner wall of the sleeve of the constant resistance device and can maintain a high value. In this way, the constant resistance anchor cable can allow the surrounding rock to deform 

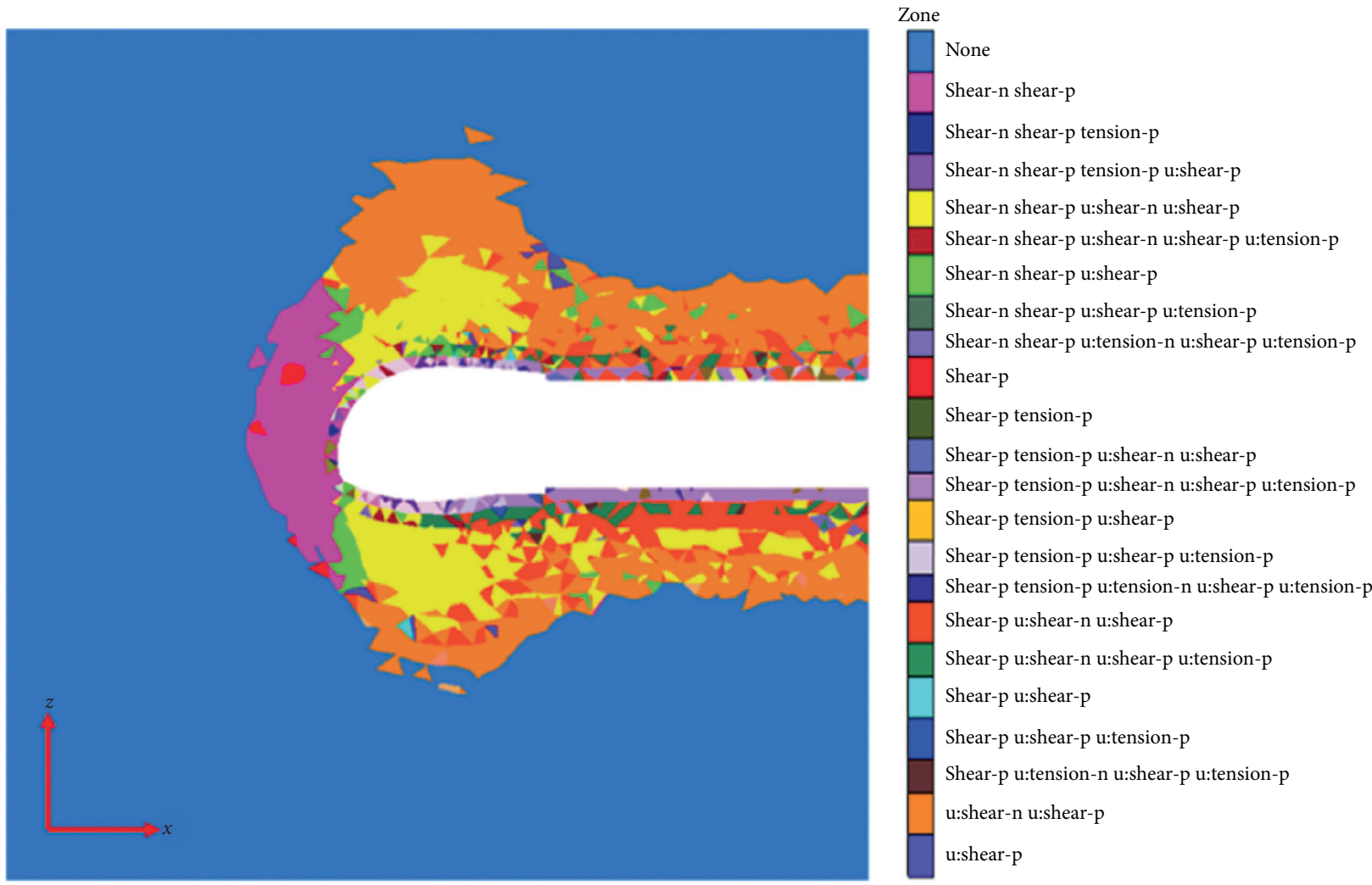

(a)

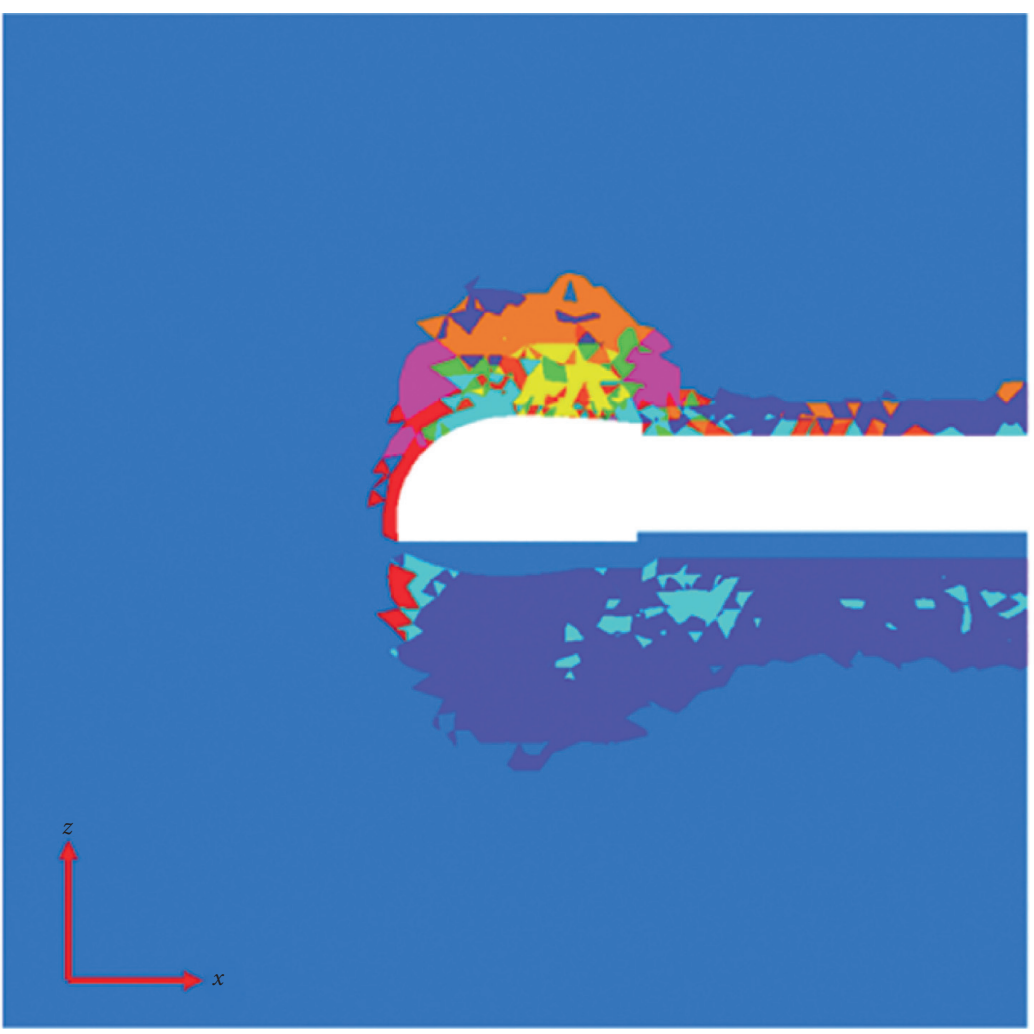

Zone

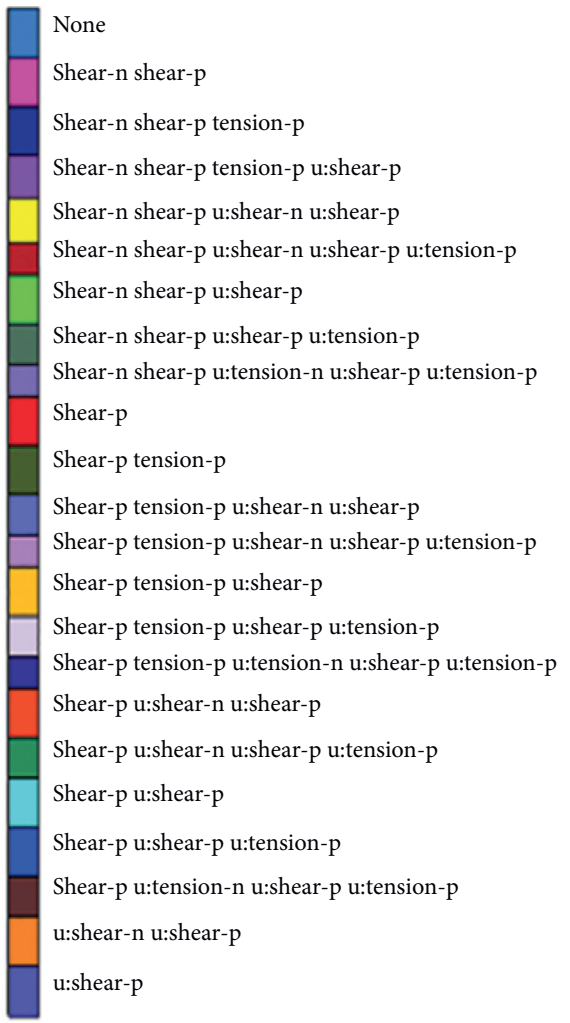

(b)

Figure 13: Characteristics of plastic zone. (a) Without support. (b) Prestressed anchor cable support. 


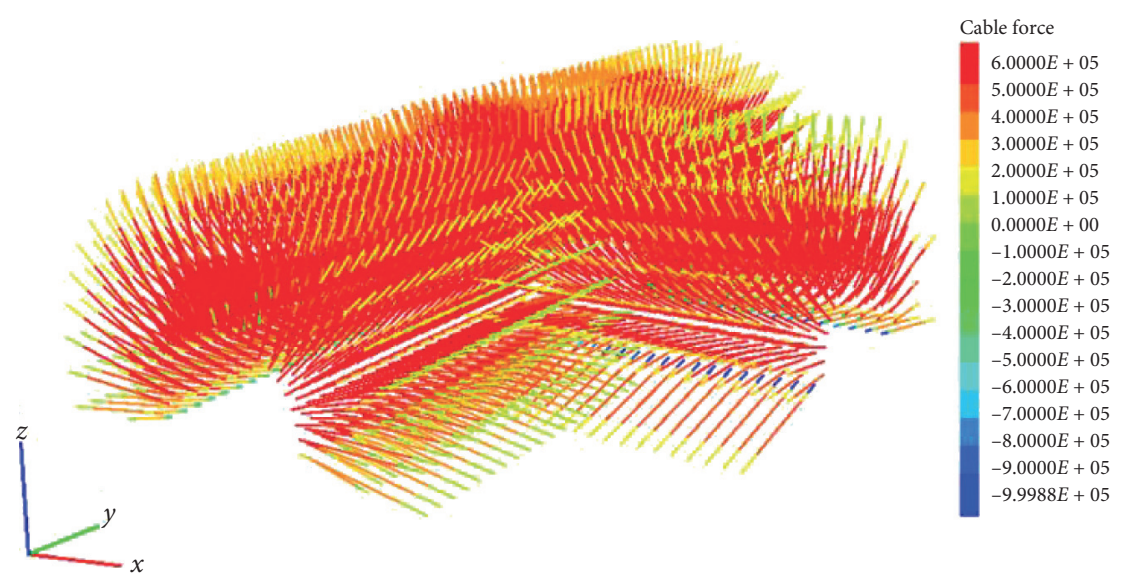

FIgURE 14: Axial force of anchor cable.

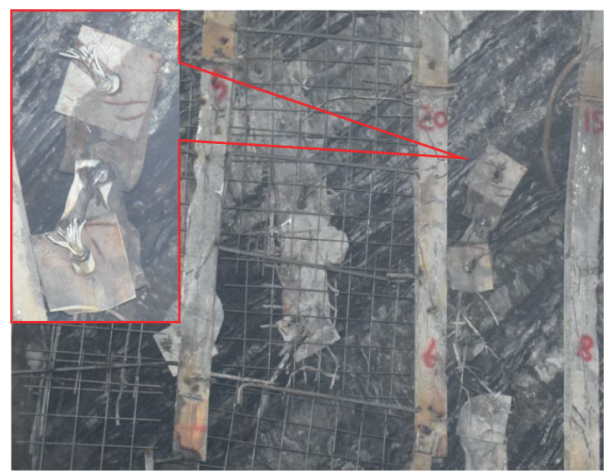

Figure 15: Release of prestressed anchor cable.

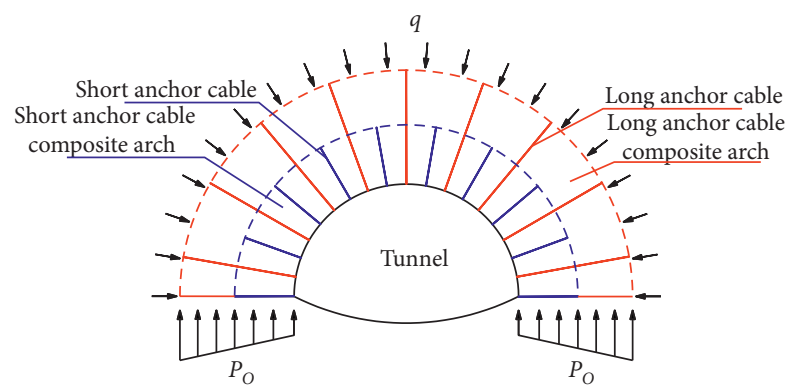

FIGURE 16: Bearing structure of double-layer composite arch.

while maintaining high prestress, and reduce the possibility of the anchor cable breaking or being pulled out. Because the constant resistance anchor cable can apply higher prestress than the ordinary anchor cable, the bearing capacity of the double-layer composite arch structure formed by the constant resistance long anchor cables and the constant resistance short anchor cables will be higher than that formed by the traditional anchor cables. Moreover, the constant resistance anchor cable has a high elongation and will not be broken, so it can make the double-layer composite arch keep high bearing capacity and allow the surrounding rock to deform properly. The double-layer composite arch structure composed of long prestressed constant resistance anchor cables and short prestressed constant resistance anchor cables can effectively prevent the failure of ordinary anchor cable leading to the damage of the double-layer composite arch and the large deformation of surrounding rock.

According to the constitutive relation of constant resistance and large deformation anchor cable [17], constant resistance anchor cable support uses its constant resistance force, so the support force of anchor cable can be regarded as constant force:

$$
Q_{0}=2 \pi I_{s} I_{c} f
$$

where $I_{c}$ is the geometric parameter, $I_{s}$ is the elastic parameter of the sleeve, and $f$ is the static friction coefficient.

Let the constant resistance force $Q_{0}=Q_{l}=Q_{s}$ in formula (3), and bring it into formula (1) to get

$$
q_{o}=2 \pi I_{s} I_{c} f \frac{1+\sin \varphi_{b}}{1-\sin \varphi_{b}}\left[\frac{\left(L_{l}-D_{a}^{\prime}\right)}{D_{a}^{\prime} D_{b}^{\prime}\left(R+L_{l}-D_{a}^{\prime}\right)}+\frac{\left(L_{s}-D_{a}\right)}{D_{a} D_{b}\left(R+L_{s}-D_{a}\right)}\right] .
$$

In this way, the relationship between the parameters of the constant resistance anchor cable and the bearing capacity of the surrounding rock can be obtained, which provides a quantitative basis for the constant resistance anchor cable support measures of the tunnel.

4.3. Constant Resistance Anchor Cable Support Scheme for Intersection of Tunnel. Based on the above numerical 


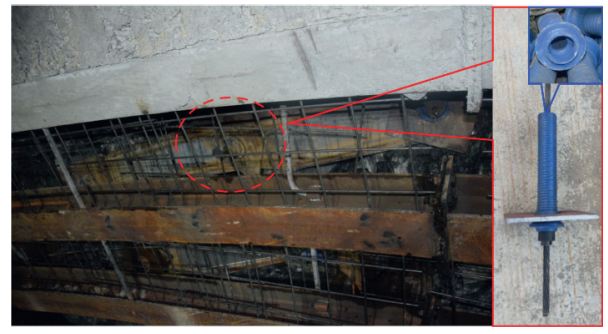

(a)

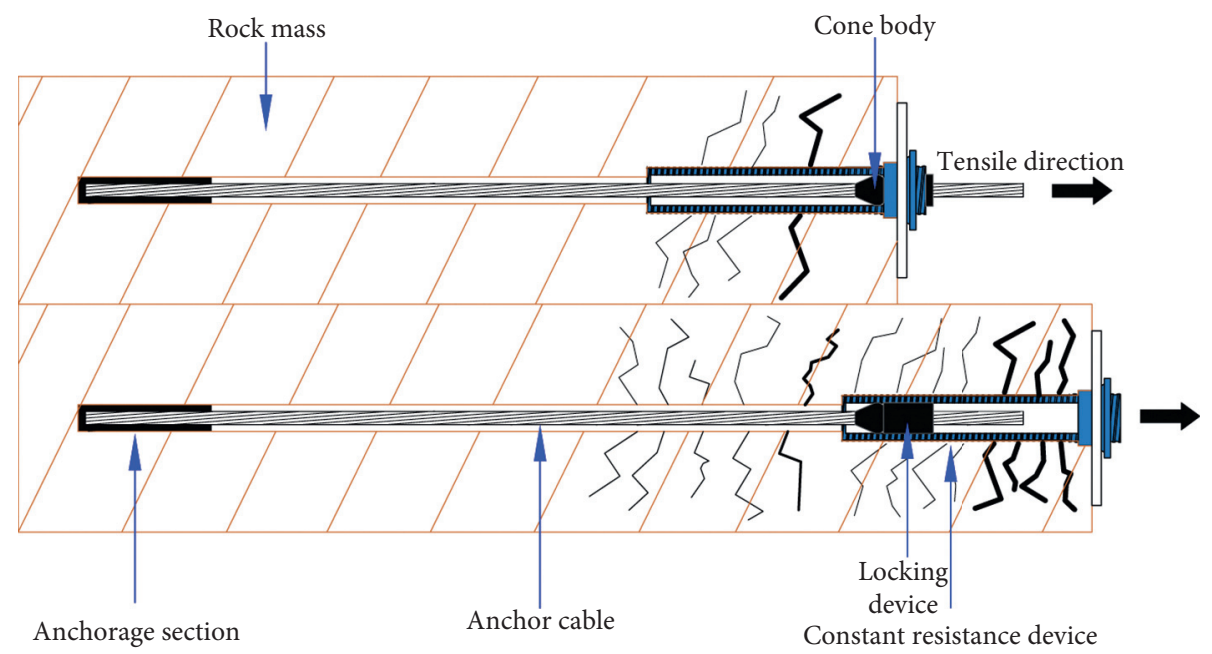

(b)

Figure 17: Constant resistance and large deformation anchor cable. (a) Photos of constant resistance anchor cable support. (b) Working principle of constant resistance anchor cable.

analysis and theoretical analysis, the combined support method of the long and short constant resistance anchor cable was proposed. The excavation scheme of the tunnel intersection was the original design of three-bench excavation, replacing the original bolt support system with the constant resistance anchor cable support system, as shown in Figure 18. This construction method was applied in inclined shaft $3 \#$ intersection, and the specific construction procedures are as follows:

(1) The top of the pilot tunnel is used as the middle position of the arch at the intersection. The size of the excavation area is $4.5 \mathrm{~m} * 4.5 \mathrm{~m}$. Due to the small excavation area, the footage of the excavation is set to $1 \mathrm{~m}$. At the same time, the long and short constant resistance anchor cables are alternately arranged to support protection; anchor cable prestress is applied at $350 \mathrm{kN}$. The length direction of the steel strip is parallel to the direction of the main tunnel.

(2) After entering the main tunnel, because the surrounding rock is affected by the rock structure, the roof of the tunnel intersection may have asymmetric deformation; that is, the deformation of the surrounding rock of the two working faces is different. Therefore, the excavation footage is set at $0.5 \mathrm{~m}$ in the mileage direction with larger deformation and $0.8 \mathrm{~m}$ in the mileage direction with relatively small deformation. Then, with the excavation of different benches, the corresponding constant resistance anchor cable support is carried out.

(3) The steel arch support shall be carried out immediately after each cycle of anchor cable construction. There is a distance between the steel arch and the surrounding rock to allow the deformation of the surrounding rock, which is set as $500 \mathrm{~mm}$. After the steel support is completed, the C25 early strength concrete shall be sprayed.

\section{Analysis of Monitoring Results}

5.1. Field Test Project. The stability of the surrounding rock of the tunnel intersection under the constant resistance anchor cable support was tested by the anchor cable axial force monitoring, surrounding rock pressure monitoring, and deep displacement monitoring. The installation of field test equipment is shown in Figure 19. The location of the monitoring section and the location of the monitoring points are shown in Figure 20.

5.2. Deep Displacement Analysis. The deep displacement can reflect the stability of the rock mass in the surrounding rock under the constant resistance anchor support. The vaults of the two intersections of inclined shaft 2\# and inclined shaft $3 \#$ were selected as the monitoring locations. The measuring depth was $1 \mathrm{~m}, 3 \mathrm{~m}, 5 \mathrm{~m}, 7 \mathrm{~m}$, and $10 \mathrm{~m}$ from the 


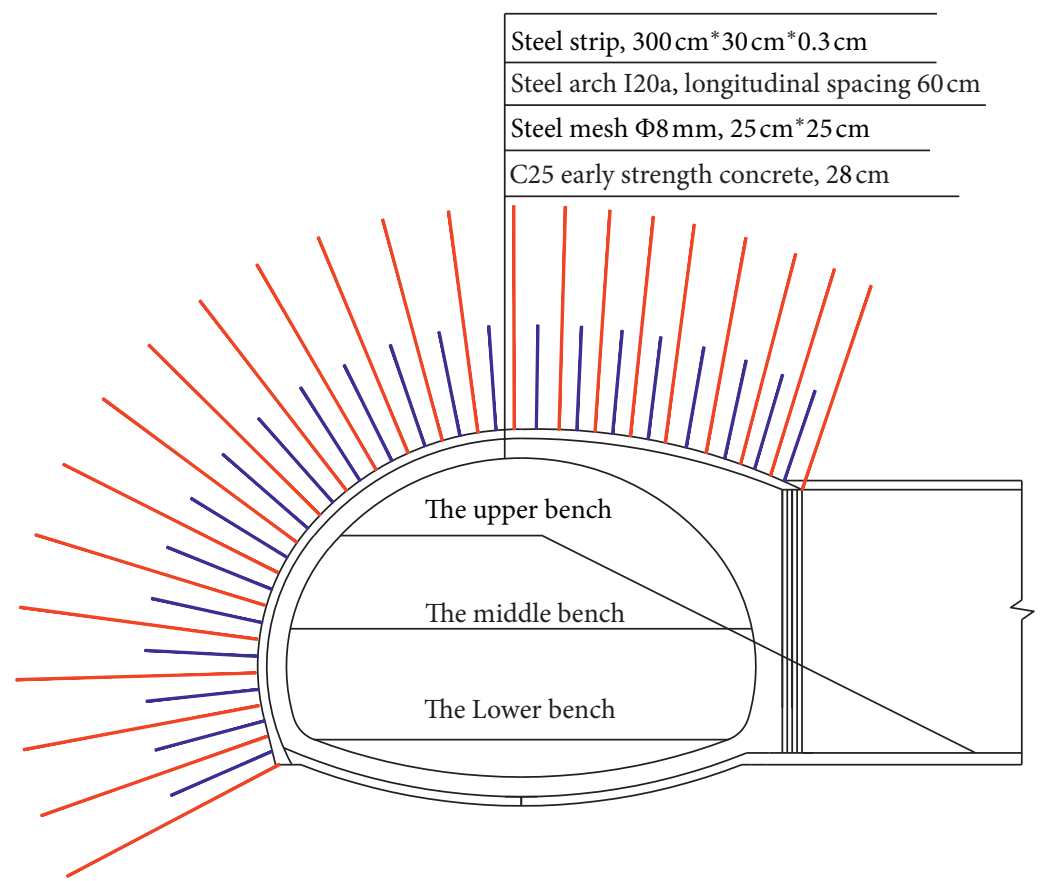

NPR constant resistance and large deformation anchor cable $\Phi 21.8 \mathrm{~mm}$, $10 \mathrm{~m}$ length spacing $100 \mathrm{~cm} \times 120 \mathrm{~cm}$

- NPR constant resistance and large deformation anchor cable $\Phi 21.8 \mathrm{~mm}$, $5 \mathrm{~m}$ length spacing $100 \mathrm{~cm} \times 120 \mathrm{~cm}$

(a)

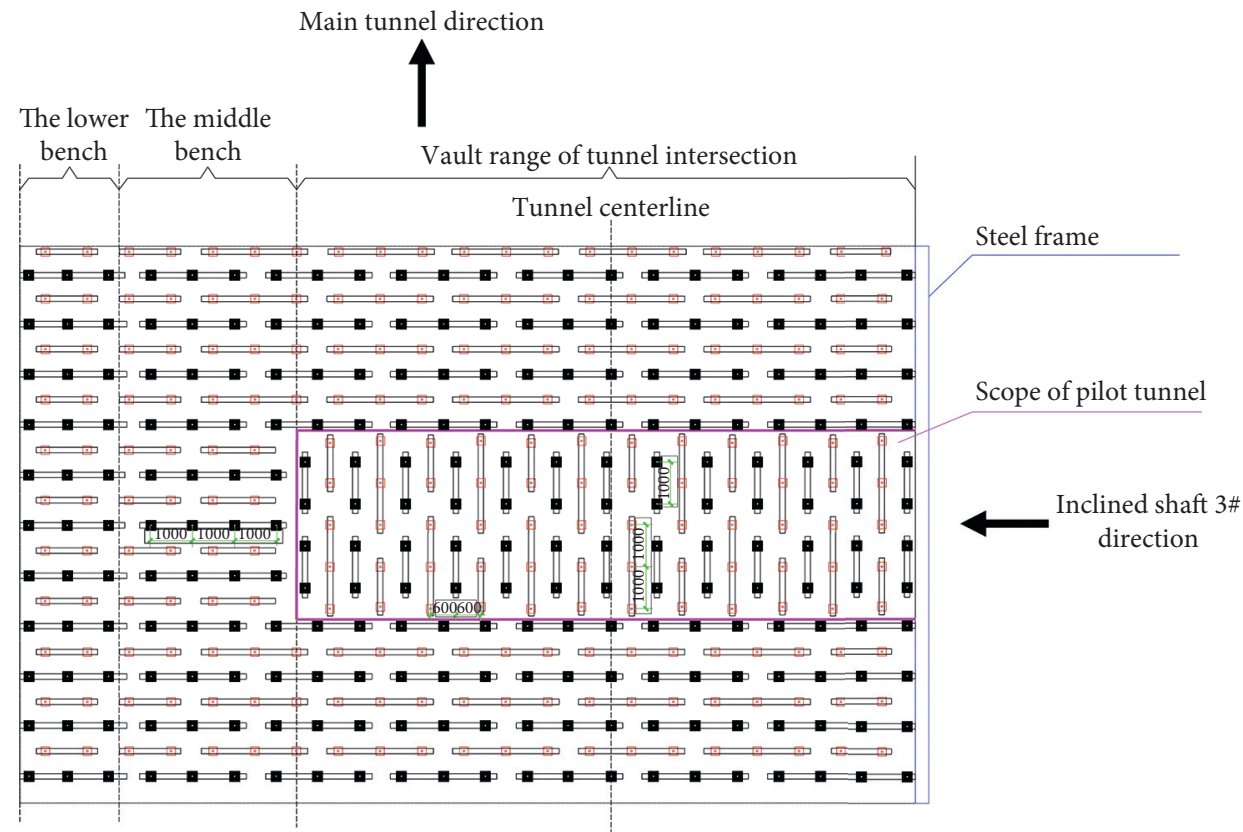

๑PR constant resistance and large deformation anchor cable $\Phi 21.8 \mathrm{~mm}$, $10 \mathrm{~m}$ length, spacing $100 \mathrm{~cm} \times 120 \mathrm{~cm}$

- NPR constant resistance and large deformation anchor cable $\Phi 21.8 \mathrm{~mm}$, $5 \mathrm{~m}$ length, spacing $100 \mathrm{~cm} \times 120 \mathrm{~cm}$

$\square$ Steel strip, $300 \mathrm{~cm} \times 30 \mathrm{~cm} \times 0.3 \mathrm{~cm}$

(b)

FIGURE 18: Constant resistance support scheme of tunnel intersection. (a) Cross section of the tunnel supported by the NPR anchor cable. (b) Tunnel annular arrangement of the NPR anchor cable. 


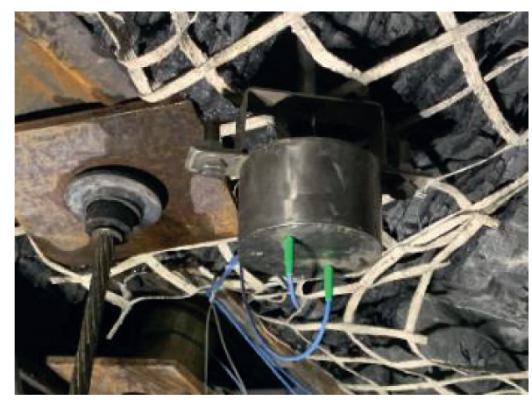

(a)

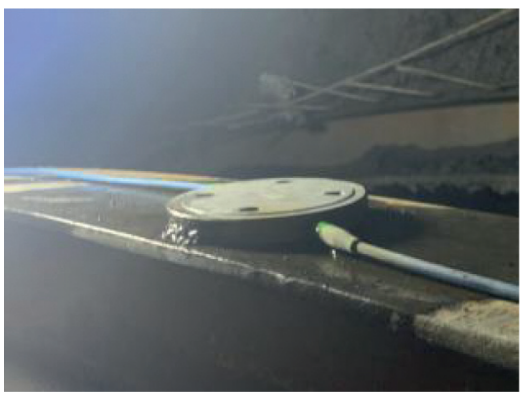

(b)

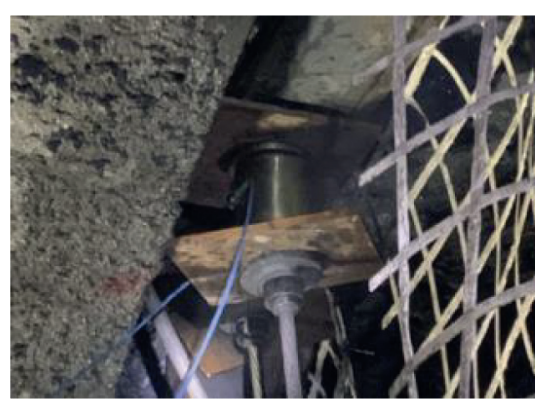

(c)

FIgURE 19: Field monitoring instruments. (a) Deep displacement meter. (b) Stress gauge. (c) Axial force gauge.

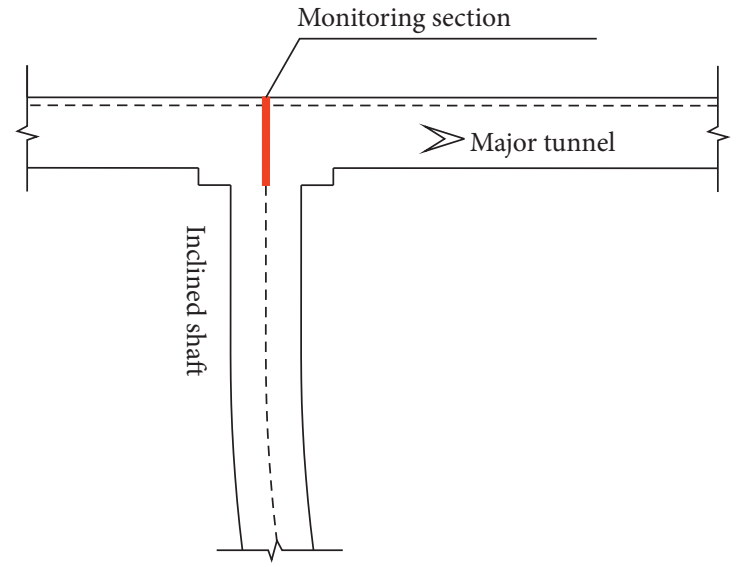

(a)

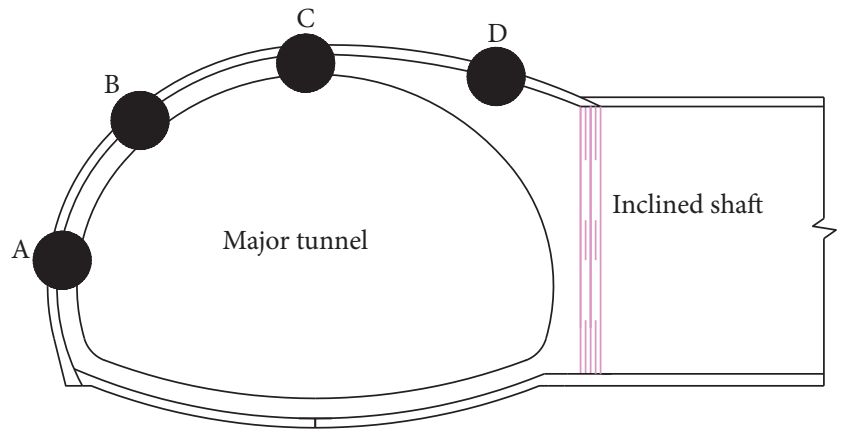

(b)

FIGURE 20: Location of monitoring. (a) Location of monitoring section. (b) Location of monitoring points.

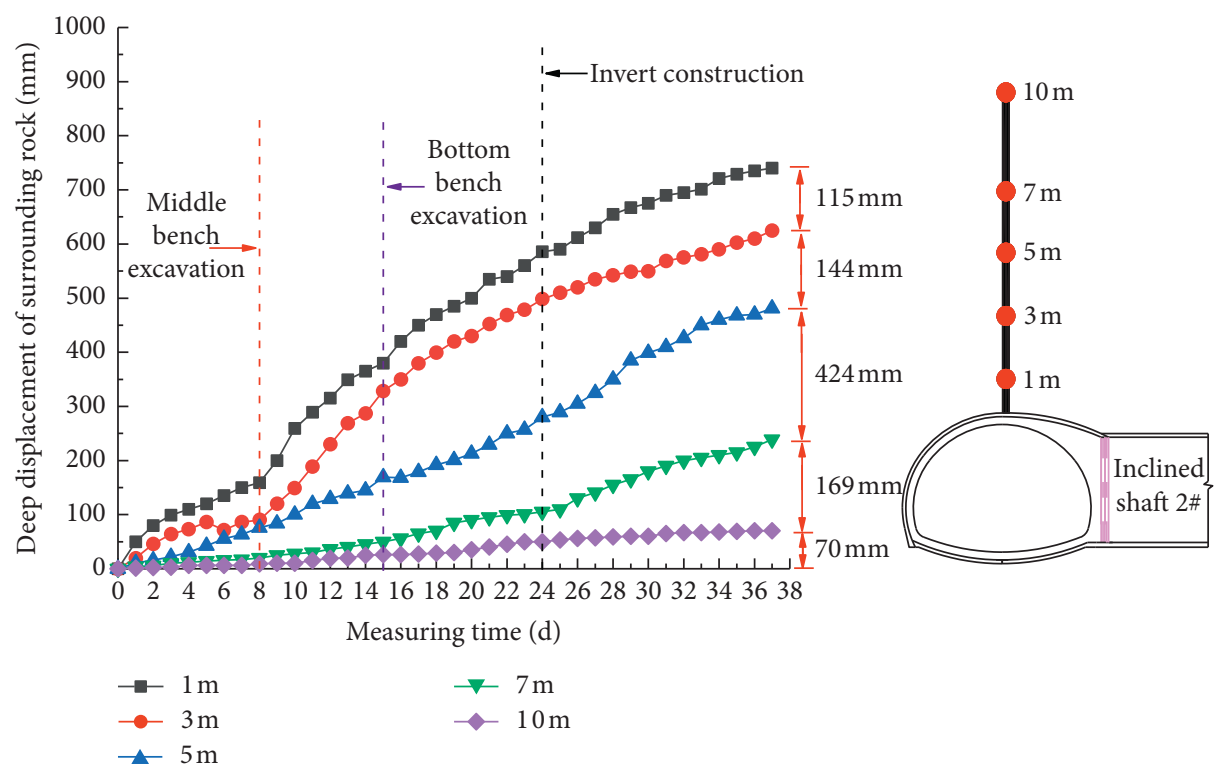

(a)

Figure 21: Continued. 


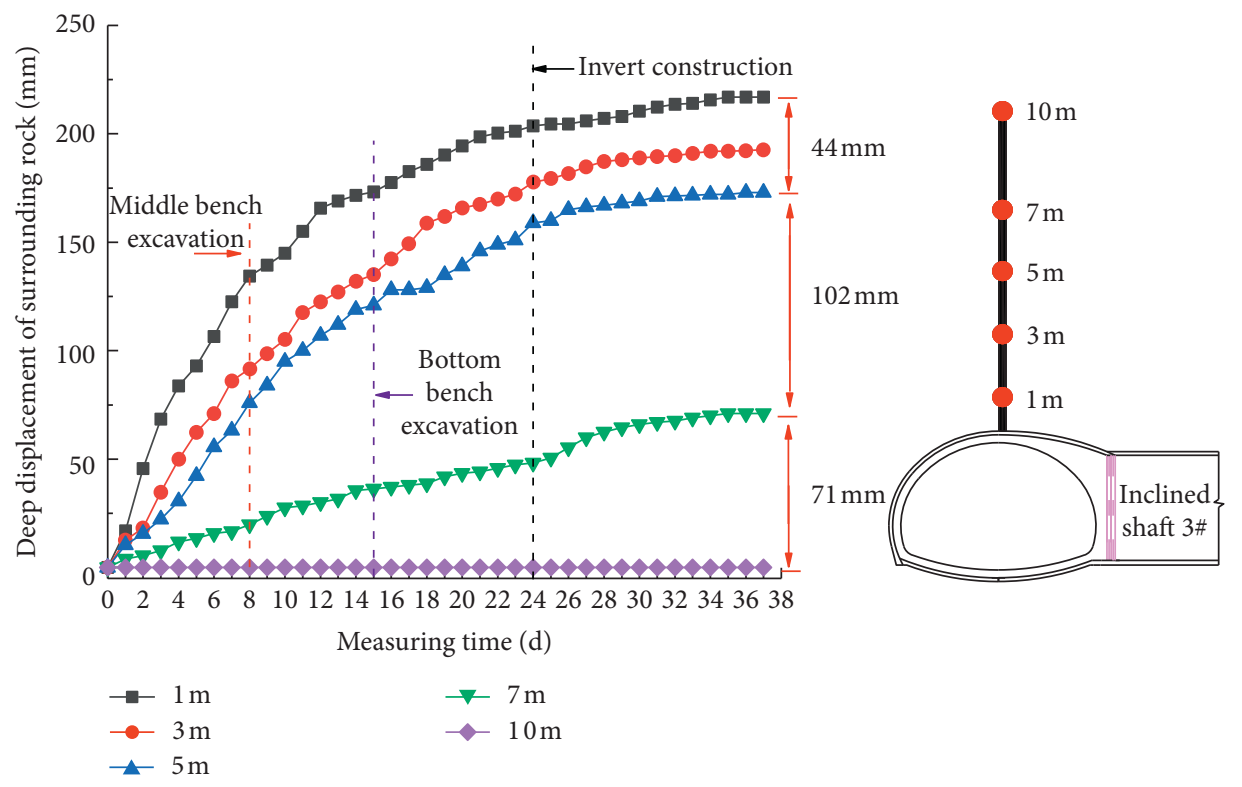

(b)

Figure 21: Deep displacement of surrounding rock. (a) Deep displacement of inclined shaft 2\# intersection. (b) Deep displacement of inclined shaft $3 \#$ intersection.

surrounding rock surface, respectively. The monitoring results showed that the measurement point at the depth of $10 \mathrm{~m}$ in the inclined shaft 2\# was displaced (Figure 21(a)), and the measurement point at the depth of $10 \mathrm{~m}$ in the inclined shaft $3 \#$ remained static without displacement (Figure 21(b)). Therefore, the plastic zone of surrounding rock of inclined shaft 3\# intersection was less than $10 \mathrm{~m}$ under the support of constant resistance anchor cable, while the plastic zone of inclined shaft $2 \#$ intersection developed to $10 \mathrm{~m}$ deep of surrounding rock (traditional bolt support). With the increase of the excavation footage, the surrounding rock in the $10 \mathrm{~m}$ depth range of the inclined shaft $3 \#$ had stabilized after a period of time, while the deep surrounding rock displacement of the inclined shaft $2 \#$ had a developing trend. The relative displacement distribution of deep surrounding rock of inclined shaft $2 \#$ is relatively uniform. The relative displacement of surrounding rock of inclined 3\# shaft mainly occurred within $1 \mathrm{~m}-7 \mathrm{~m}$ inside the surrounding rock, but the relative displacement of the surrounding rock was relatively small within $1 \mathrm{~m}-5 \mathrm{~m}$, which showed that the short anchor cable plays a role in improving the self-supporting capacity of the surrounding rock. At the same time, the long anchor cable fully mobilized the deep surrounding rock and together with the shallow surrounding rock improved the stability of the surrounding rock within the whole coverage of the anchor cable [18].

5.3. Analysis of Pressure between Surrounding Rock and Primary Support. According to the test results of the surrounding rock pressure of the steel arch shown in Figure 22, the point A pressure at the arch waist was the smallest, and the point $D$ pressure at the vault was the largest. However,

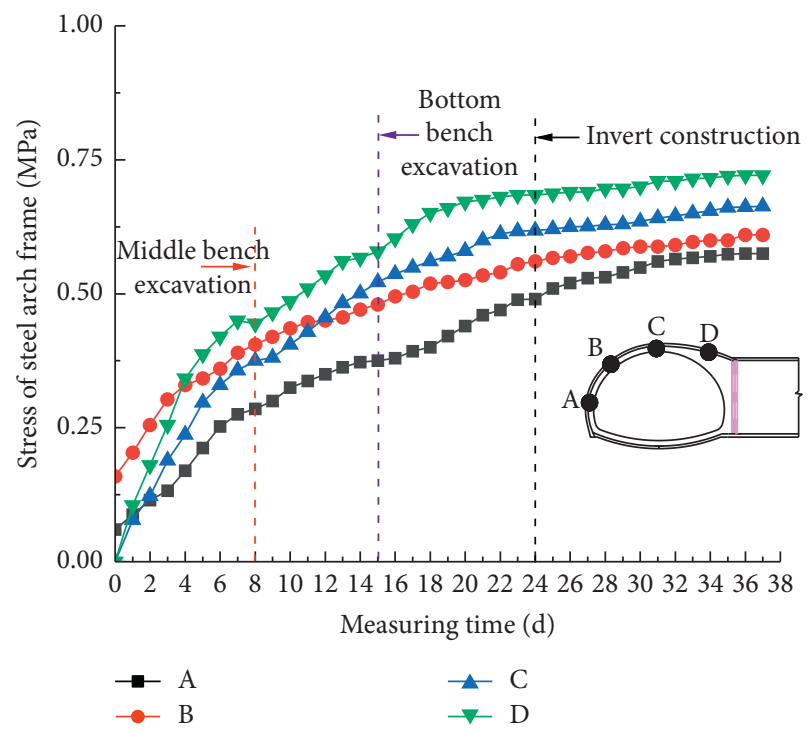

Figure 22: Pressure of surrounding rock.

the maximum difference between the pressure values of all measuring points was about $0.15 \mathrm{MPa}$, which was not much different. Therefore, the high prestressed constant resistance anchor cable can homogenize the stress of surrounding rock, reduce the concentrated pressure on the steel arch frame, and play a positive role in the stability of the primary support.

5.4. Force Analysis of Anchor Cable. As shown in Figure 23, the prestress applied by the anchor cable was $350 \mathrm{kN}$, and the prestress loss was about $50 \mathrm{kN}$. The axial force of the anchor 


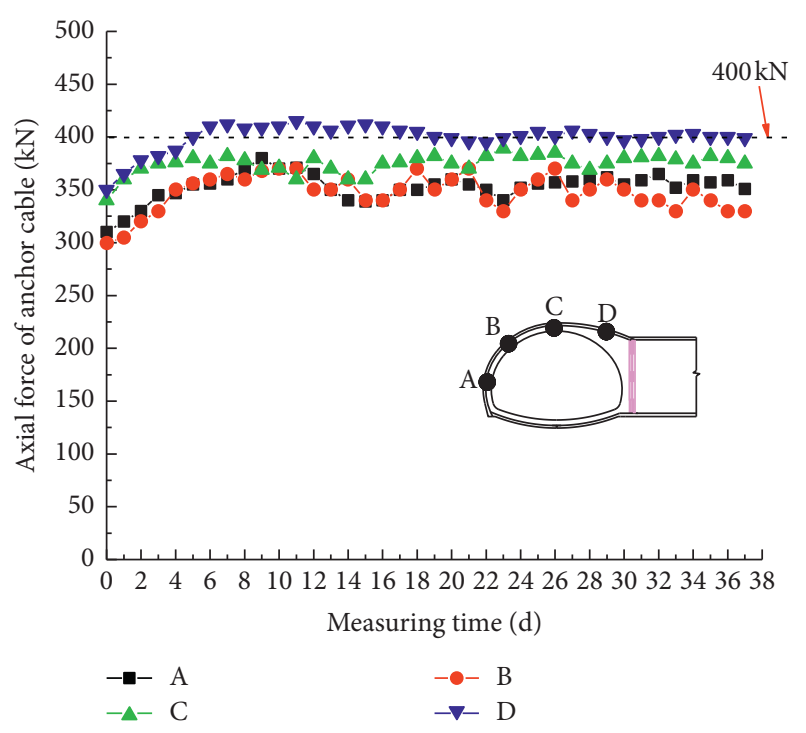

Figure 23: Axial force of anchor cable.

cable at the measuring point $D$ near the inclined shaft at the vault was maintained at about $400 \mathrm{kN}$, which was slightly higher than that at other positions. But the axial force of all anchor cables maintained a fixed value after a period of support and would not increase anymore. It can be concluded that the axial force of the anchor cable was higher in the surrounding rock stress concentration area, but due to the presence of the constant resistance device, the anchor cables will not break or pull out under higher axial force and are always in good condition working status.

\section{Conclusion}

This paper introduces the application of high prestressed constant resistance and large deformation anchor cable at the intersection of the tunnel. Through numerical simulation, theoretical analysis, and field test, the following conclusions are drawn:

(1) Through field geological survey, Flac3D numerical simulation software was used to analyze the large deformation characteristics of the surrounding rock at the intersection of the Muzhailing tunnel and the inclined shaft 3\#. The stress distribution of the surrounding rock is uneven, and the stress concentration is obvious. The main deformation of the surrounding rock is the sliding deformation and the squeezing bending deformation, and it shows the asymmetric shape. The maximum deformation of the surrounding rock is more than $1 \mathrm{~m}$. The plastic zone extends large without support. Under the support of prestressed anchor cable, the large deformation and plastic zone of the surrounding rock is controlled, and the strength of surrounding rock on the tunnel surface is improved, but the anchor cable exceeds its yield strength.

(2) According to the deformation characteristics of tunnel surrounding rock, a high prestressed constant resistance and large deformation anchor cable support method is proposed. Through theoretical analysis, the relationship between the parameters of constant resistance anchor cable support and the bearing capacity of surrounding rock is obtained. In this method, long and short anchor cables are used to support the surrounding rock to form a double-layer composite arch structure, which can greatly improve the bearing capacity of the surrounding rock.

(3) The field monitoring experiment results show that the plastic zone of surrounding rock does not exceed the coverage of anchor cable $(10 \mathrm{~m})$ under the support of long and short anchor cables. The anchor cable works well under the condition of high prestress. The uniform stress of the steel arch frame shows that the constant resistance anchor cable makes the internal stress of the surrounding rock uniform and reduces the stress concentration. Therefore, the new type of supporting structure is of great significance for controlling large deformation of weak and broken surrounding rocks.

\section{Data Availability}

The data used to support the findings of this study are available from the corresponding author upon request.

\section{Conflicts of Interest}

The authors declare that they have no conflicts of interest.

\section{Acknowledgments}

This work was supported by the National Natural Science Foundation of China (Grant No. 41941018) and also by Gansu Provincial Science and Technology Program (Grant No. 19ZD2GA005).

\section{References}

[1] E. Hoek, P. G. Marinos, and V. P. Marinos, "Characterisation and engineering properties of tectonically undisturbed but lithologically varied sedimentary rock masses," International Journal of Rock Mechanics and Mining Sciences, vol. 42, no. 2, pp. 277-285, 2005.

[2] O. Aydan, T. Akagi, and T. Kawamoto, "The squeezing potential of rocks around tunnels; theory and prediction," Rock Mechanics and Rock Engineering, vol. 26, no. 4, pp. 137-163, 1993.

[3] Y. Kang, Q. Liu, G. Gong, and H. Wang, "Application of a combined support system to the weak floor reinforcement in deep underground coal mine," International Journal of Rock Mechanics and Mining Sciences, vol. 71, pp. 143-150, 2014.

[4] Z. Tao, C. Zhu, X. Zheng et al., "Failure mechanisms of soft rock roadways in steeply inclined layered rock formations," Geomatics, Natural Hazards and Risk, vol. 9, no. 1, pp. 1186-1206, 2018.

[5] M. C. He, "Physical modeling of an underground roadway excavation in geologically $45^{\circ}$ inclined rock using infrared thermography," Engineering. Geology, vol. 121, no. 3-4, pp. 165-176, 2011. 
[6] H.-l. Liu, S.-c. Li, L.-p. Li, and Q.-q. Zhang, "Study on deformation behavior at intersection of adit and major tunnel in railway," KSCE Journal of Civil Engineering, vol. 21, no. 6, pp. 2459-2466, 2017.

[7] H. Wang, X. Guo, M. Jiang, and G. B. Crosta, "Investigation of rock bolting for deeply buried tunnels via a new efficient hybrid DEM-analytical model," Tunnelling and Underground Space Technology, vol. 82, pp. 366-379, 2018.

[8] Q. Meng, H. Zhao, and C. Zhu, "Analytical and reliability study of the tunnel with rockbolts in rock masses," Periodica Polytechnica Civil Engineering, vol. 62, no. 3, pp. 783-791, 2018, https://www.researchgate.net/scientific-contributions/ 83954045-Zhongliang-Ru.

[9] F. Xu, S.-c. Li, Q.-q. Zhang, L.-p. Li, S.-s. Shi, and Q. Zhang, "A new type support structure introduction and its contrast study with traditional support structure used in tunnel construction," Tunnelling and Underground Space Technology, vol. 63, pp. 171-182, 2017.

[10] F. Y. Hsiao, C. L. Wang, and J. C. Chern, "Numerical simulation of rock deformation for support design in tunnel intersection area," Tunnelling and Underground Space Technology, vol. 24, no. 1, pp. 14-21, 2009.

[11] P. Lin, Y. Zhou, H. Liu, and C. Wang, "Reinforcement design and stability analysis for large-span tailrace bifurcated tunnels with irregular geometry," Tunnelling and Underground Space Technology, vol. 38, pp. 189-204, 2013.

[12] E. Hoek and M. S. Diederichs, "Empirical estimation of rock mass modulus," International Journal of Rock Mechanics and Mining Sciences, vol. 43, no. 2, pp. 203-215, 2006.

[13] E. Hoek, C. T. Carranza-Torres, and B. Corkum, "HoekBrown failure criterion-2002 edition," in Proceedings of the 5th North American Rock Mechanics Symposium, pp. 267-273, Toronto, Canada, July 2002.

[14] L. W. Zhang and R. Wang, "Research on status quo of anchorage theory of rock and soil," Rock and Soil Mechanics, vol. 23, no. 5, pp. 627-631, 2002.

[15] H. F. Gong, W. J. Zhang, and X. Q. Li, "Discussion about rational parameters of supporing with combined arch," Coal Mining Technology, vol. 1, pp. 42-44, 2002.

[16] W. J. Yu, Q. Gao, and C. Q. Zhu, "Study of strength theory and application of overlap arch bearing body for deep soft surrounding rock," Chinese Journal of Rock Mechanics and Engineering, vol. 29, no. 10, pp. 2134-2142, 2010.

[17] M. He, W. Gong, J. Wang et al., "Development of a novel energy-absorbing bolt with extraordinarily large elongation and constant resistance," International Journal of Rock Mechanics and Mining Sciences, vol. 67, no. 1, pp. 29-42, 2014.

[18] F. T. Dong, H. W. Song, Z. H. Guo et al., "Roadway support theory based on broken rock zone," Journal of China Coal Society, vol. 19, no. 1, pp. 21-32, 1994. 